
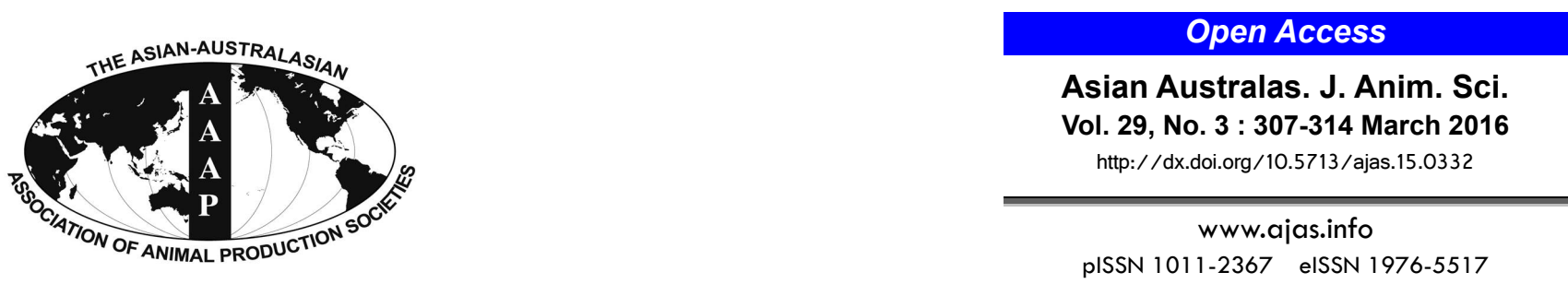

\title{
Cheese Microbial Risk Assessments - A Review
}

\author{
Kyoung-Hee Choi ${ }^{1,2}$, Heeyoung Lee ${ }^{3}$, Soomin Lee ${ }^{3}$, Sejeong Kim ${ }^{3}$, and Yohan Yoon ${ }^{3, *}$ \\ ${ }^{1}$ Department of Oral Microbiology, College of Dentistry, Wonkwang University, Iksan 570-749, Korea
}

\begin{abstract}
Cheese is generally considered a safe and nutritious food, but foodborne illnesses linked to cheese consumption have occurred in many countries. Several microbial risk assessments related to Listeria monocytogenes, Staphylococcus aureus, and Escherichia coli infections, causing cheese-related foodborne illnesses, have been conducted. Although the assessments of microbial risk in soft and low moisture cheeses such as semi-hard and hard cheeses have been accomplished, it has been more focused on the correlations between pathogenic bacteria and soft cheese, because cheese-associated foodborne illnesses have been attributed to the consumption of soft cheeses. As a part of this microbial risk assessment, predictive models have been developed to describe the relationship between several factors $(\mathrm{pH}, \mathrm{Aw}$, starter culture, and time) and the fates of foodborne pathogens in cheese. Predictions from these studies have been used for microbial risk assessment as a part of exposure assessment. These microbial risk assessments have identified that risk increased in cheese with high moisture content, especially for raw milk cheese, but the risk can be reduced by preharvest and postharvest preventions. For accurate quantitative microbial risk assessment, more data including interventions such as curd cooking conditions (temperature and time) and ripening period should be available for predictive models developed with cheese, cheese consumption amounts and cheese intake frequency data as well as more dose-response models. (Key Words: Predictive Model, Cheese, Microbial Risk Assessment)
\end{abstract}

\section{INTRODUCTION}

Cheese is popular in many countries (CDIC, 2014) because of the associated health benefits and flavour. The health benefits of cheese include natural probiotic and antitumour properties (Goldin and Gorbach, 1992). Additionally, cheese is a rich source of dietary calcium (IOM, 2011), phosphorus, and proteins (USDA, 2011), and has been shown to reduce the incidence of type II diabetes (Mozaffarian et al., 2010).

Although cheese is generally considered a safe food because of the physicochemical and antagonistic properties of lactic acid bacteria, $0.4 \%$ of all foodborne outbreaks were related to contaminated cheese in 2006 in the

\footnotetext{
* Corresponding Author: Yohan Yoon. Tel: +82-2-2077-7585, Fax:+82-2-710-9479, E-mail: yyoon@sookmyung.ac.kr

${ }^{2}$ Institute of Biomaterials-Implant, Wonkwang University, Iksan 570-749, Korea.

3 Department of Food and Nutrition, Sookmyung Women's University, Seoul 140-742, Korea.

Submitted Apr. 17, 2015; Revised Jun. 7, 2015; Accepted Jul. 10, 2015
}

European Union (Kousta et al., 2010). Many of these foodborne outbreaks were a result of contamination with Staphylococcus aureus, and this was not surprising as $S$. aureus often causes mastitis in cows, leading to milk contamination (Rabello et al., 2007). Additionally, in the USA, S. aureus and Listeria monocytogenes were isolated from unpasteurized soft cheese on sale in California, which was smuggled into the USA from Mexico in 2010 (MDA, 2010). This implication may have resulted from the properties of soft cheese like the high water activity and low acidity as well as improper sanitation that is common route for pathogenic bacteria to contaminate the cheese during cheese-making process (Gould et al., 2014). Further, $L$. monocytogenes was often found in soft cheese, which has high moisture content: $67 \%$ of moisture on a fat-free basis or $\geq 50 \%$ of moisture content (Codex, 2000; FDA, 2012a). This data suggest that cheese may pose a significant risk to consumers (Janštovă et al., 2014). Given this picture, strict guidelines have been established to control foodborne pathogens in cheese, especially for L. monocytogenes (FDA, 2003; EFSA/ECDC, 2011). For instance, for cheese with an 
average $\mathrm{pH}$ greater than 5 and an average Aw above 0.94 along with a shelf life of more than 5 days, European Union law requires 0 colony-forming unit (CFU) of $L$. monocytogenes in five $25 \mathrm{~g}$ cheese samples at the time of production, and less than $100 \mathrm{CFU} / \mathrm{g}$ in five samples at the point of sale (European Commission, 2007).

Predictive models have been used to estimate kinetic parameters in microbial risk assessments and to predict the effect of various factors on the behaviour of foodborne pathogens in cheese, which results are used in microbial risk assessments. Australia and New Zealand conducted microbial risk assessment for Campylobacter jejuni, enterohemorrhagic Escherichia coli, Salmonella, S. aureus, and L. monocytogenes in raw milk cheese (Food Standards, 2009). Additionally, the joint Food and Drug Administration (FDA)/Health Canada commission quantitatively analysed the risk of L. monocytogenes in soft-ripened cheese, and this cheese was categorized as 'low risk' in the $L$. monocytogenes risk assessment in ready-to-eat foods (FDA/USDA, 2003; FDA, 2012a). Further, Lake et al. (2005a) conducted a microbial risk assessment for $L$. monocytogenes in low moisture cheese in New Zealand. As presented above, many risk assessments have been conducted for cheese due to their varied properties such as $\mathrm{pH}, \mathrm{Aw}$, lactic acid bacteria, and foodborne pathogen content. Given this information, the objective of this communication was to review published literatures on aspects of microbial risk assessment in cheese.

\section{FOODBORNE ILLNESS LINKED TO CHEESE CONSUMPTION}

Foodborne illnesses related to cheese consumption have occurred in many countries. S. aureus infections have been linked to the use of unpasteurized milk or to contamination due to improper handling because the pathogen at more than $5 \mathrm{Log} \mathrm{CFU} / \mathrm{mL}$ produces heat-resistant enterotoxin (Ryser, 2001; Delbes et al., 2006; CDC, 2010a). Intake of 20 to $1,000 \mathrm{ng}$ of the enterotoxin can cause typical symptoms of $S$. aureus infection (Normanno et al., 2007; Pelisser et al., 2009). In England, consumption of S. aureus enterotoxin contaminated Stilton cheese (internally moldripened semisoft blue cheese produced by using Penicillium roqueforti) caused 155 illnesses (Maguire et al., 1991; Johnson, 2001). In the USA, cheese has also been a food vector for S. aureus foodborne outbreaks (CDC, 2014a). In 1981, improper cheese pasteurization led to 16 cases of $S$. aureus foodborne illness in USA (Altekruse et al., 1998; Le Loir et al., 2003). In 1999, Minas cheese (soft cheese) made from raw bovine milk caused two outbreaks in Brazil affecting 378 individuals (Simeão do Carmo et al., 2002). Recently, six $S$. aureus outbreaks occurred in France due to consumption of enterotoxin type $\mathrm{E}$ in soft cheese that was processed during weeks 40 and 41 (Ostyn et al., 2010).

Cheese-related $L$. monocytogenes outbreaks have had a relatively high fatality rate (15\% to $30 \%$ ) (Makino et al., 2005; FDA, 2012b), leading to increased public awareness of this infection. Clinically, L. monocytogenes causes sepsis and meningitis in immunocompromised individuals (e.g., transplant patients, elderly patients receiving chemotherapy, individuals with diabetes or liver disease), and around $25 \%$ of the invasive listeriosis cases occur in pregnant women (Wing and Gregory, 2002). Of 13 L. monocytogenes serotypes, three $(1 / 2 \mathrm{a}, 1 / 2 \mathrm{~b}$, and $4 \mathrm{~b})$ account for more than $95 \%$ of human illnesses due to $L$. monocytogenes (Kathariou, 2002). In 2005, 10 cases of L. monocytogenesinduced listeriosis occurred in a small northwestern Swiss town with three fatalities due to bacteraemia. Eight of these cases were in older immuno compromised patients, while two cases occurred in pregnant women leading to abortion. This outbreak occurred after these patients had Tomme (soft cheese) contaminated with $L$. monocytogenes serotype $1 / 2 \mathrm{a}$ (Bille et al., 2006). Fretz et al. (2010) reported that Quargel (acid curd cheese) contaminated with $L$. monocytogenes serotype 1/2a caused four deaths out of 14 cases in Austria and Germany in 2009. In the USA, a multistate outbreak of listeriosis among pregnant women occurred between October 2008 and March 2009. These outbreaks were caused by the intake of Mexican-style cheese made from pasteurized milk (Jackson et al., 2011). In addition, there was another Mexican-style cheese-related outbreak of listeriosis in North Carolina in the USA between October 2000 and January 2001 (CDC, 2001). Recently, the CDC (2014b) announced a multistate listeriosis outbreak due to cheese products in California and Maryland. This outbreak affected eight individuals, seven of whom were hospitalized and one died. Even Japan, which has a relatively low cheese consumption compared to the western countries, also had $L$. monocytogenes serotype $1 / 2 \mathrm{~b}$ outbreaks due to cheese consumption resulting in 86 cases of $L$. monocytogenes infection (Makino et al., 2005).

Salmonella is a well-recognized foodborne pathogen. All Salmonella strains are gastroenteritis-inducing pathogens (Ryser, 2001), and various Salmonella serotypes have been involved in cheese-borne outbreaks. Consumption of Mexican-style cheese in Kane county, Illinois, USA led to an outbreak of Salmonella Newport infections during the March 2006 through April 2007 time period, affecting 85 individuals. In the county, $S$. Newport was a rare, multidrug-resistant serotype (CDC, 2008). In 2013, Raw Cashew cheese was linked to a multistate outbreak of Salmonella Stanley in California (15 cases), Nevada (one case), and Wyoming (one case) in the US. This outbreak led to three hospitalizations (CDC, 2014c), but no fatalities. Although Salmonella Muenster is rare in Europe, the first published outbreak of $S$. Muenster was reported in 
Europe in 2008. In France, a nationwide outbreak of gastrointestinal illness due to $S$. Muenster occurred during March to April 2008 after goat cheese consumption in 25 people. Four patients were hospitalized, but no fatalities occurred (van Cauteren et al., 2009).

In cheese, shiga toxin-producing E. coli (STEC) strains such as $E$. coli $\mathrm{O} 157: \mathrm{H} 7$ are important foodborne pathogens (Gyles, 2007). In 2003, E. coli O157:H7 was linked to an unpasteurized Gouda cheese-related outbreak involving 13 cases in Canada. This outbreak resulted in two cases of lethal haemolytic uremic syndrome (Honish et al., 2005). Recently, there was a multistate outbreak of E. coli O157:H7 infections associated with Gouda cheese intake in the US. This outbreak affected 38 people in five states (Arizona, California, New Mexico, and Nevada); 15 reported hospitalizations, one showed haemolytic uremic syndrome, but no deaths occurred (CDC, 2010b). Although Gouda cheese is a hard cheese (low Aw of 0.950 to 0.970 [CCE, 2008; CDC, 2013c]), similar to Cheddar, Colby, Edam, and Swiss cheeses, E. coli O157:H7 outbreaks have occurred.

Taken together, cheese related foodborne illnesses have been generally linked to soft cheese or cheese made from raw or unpasteurized milk, but rarely in hard cheese. Hence, manufacturing process and distribution and storage process should be controlled appropriately to prevent foodborne illness by these cheeses. In addition, microbial risk assessment including predictive model for exposure assessment also should be importantly counted for microbiological safety assurance.

\section{PREDICTIVE MODELS FOR CHEESE AS A PART OF MICROBIAL RISK ASSESSMENT}

Various intrinsic and extrinsic factors in food affect the fate of foodborne pathogens. Most foodborne bacteria such as L. monocytogenes, S. aureus, Salmonella, STEC, and Yersinia enterocolitica may not grow in hard cheese $(\leq 39 \%$ of moisture content) and semi-soft cheese $(>39 \%-<50 \%$ of moisture content) such as Colby and Blue cheeses (Reiter et al., 1964; Norholt, 1984; Ryser and Marth, 1987a; Yousef and Marth, 1988; Gengeorgis et al., 1991; Kosikowski and Mistry, 1997). Many cheese-borne outbreaks have been linked to soft cheese ( $\geq 50 \%$ of moisture content), with most of these outbreaks caused by postpasteurization contamination. L. monocytogenes contamination of cheese also might be a result of raw milk contamination (MorenoEnriquez et al., 2007; Rosshaug et al., 2012). To predict the effects of these factors in food-related conditions, quantitative predictive models for microbial risk assessment have been developed for various ready-to-eat foods including cheese. To evaluate the effect of physicochemical properties in soft blue-white cheese made from pasteurized milk, Rosshaug et al. (2012) developed a tertiary model of L. monocytogenes growth to handle dynamic growth conditions. These dynamic growth conditions used time series temperature, $\mathrm{pH}, \mathrm{NaCl}$, and lactic acid data sampled from soft blue-white cheese longitudinally from pasteurization to consumption. By model simulation, Rosshaug et al. (2012) concluded that soft blue-white cheese ( $\mathrm{pH}$ : $\sim 4.9$; salt concentration: $\sim 1.8 \mathrm{~g} / 100 \mathrm{~g}$; lactic acid concentration: $\sim 0.354 \mathrm{~g} / 100 \mathrm{~g})$ supports $L$. monocytogenes growth. Schvartzman et al. (2014) also developed predictive models to describe the effects of $\mathrm{pH}$ and Aw on L. monocytogenes growth rates on surfaceripened cheese in a case of cross contamination. $L$. monocytogenes was thus inoculated into smear-ripened and mold-ripened cheese to simulate cross-contamination, and the responses of the pathogens to environmental factors such as $\mathrm{pH}$ and Aw of the cheese were evaluated by the predictive models. Schvartzman et al. (2014) found that Aw in surface-ripened cheese was not related to $L$. monocytogenes growth. A study by Ryser and Marth (1987b) showed a 10-fold increase in L. monocytogenes cell counts in Camembert cheese 24 hours after its manufacture. Cell counts were then shown to decrease during the first 18 days of ripening, with growth after day 18 due to a rise in pH. Additionally, Lee et al. (2014) showed that $S$. aureus growth in Camembert cheese was temperature-dependent because $S$. aureus did not grow in Camembert cheese at $4^{\circ} \mathrm{C}$. $Y$. enterocolitica could be isolated from cheese at low temperature because the pathogen is psychrotrophic (Moustafa, 1990). Kowalik and Lobacz (2015) also showed $Y$. enterocolitica growth in Camembert-type cheese at psychrotrophic temperatures of $3^{\circ} \mathrm{C}$ to $15^{\circ} \mathrm{C}$. Thus, the effects of $\mathrm{Aw}$ and $\mathrm{pH}$ on microbial growth in soft cheese are dependent on microorganism and storage temperature. Bozkurt and Erkmen (2001) developed predictive nonlinear models to describe the inactivation of $Y$. enterocolitica in Turkish Feta cheese during storage. The predictions of these models were compared statistically by the F-test. In this study, Bozkurt and Erkmen (2001) found that addition of starter culture (Streptococcus cremoris) had a significant $(\mathrm{p}<0.05)$ inhibitory effect on $Y$. enterocolitica, but salt had no significant $(\mathrm{p}>0.10)$ effect on both growth rate and lag phase duration of $Y$. enterocolitica. In addition to the factors listed above, the physiological status of foodborne pathogens may influence lag phase duration and the growth rate of bacteria (Fratamico et al., 2005).

As described above, most predictive models for cheese were developed to predict L. monocytogenes growth because the pathogen was considered high-risk pathogen when it contaminates in cheese. Thus, many countries applied 'zero-tolerance' policy for L. monocytogenes in cheese but non-STEC and $S$. aureus had quantitative microbial criteria rather than 'zero tolerance' policy. 
According to this fact, we suggest that predictive models for non-STEC and $S$. aureus should be developed to improve the accuracy of microbial risk assessment for the pathogens in cheese.

\section{MICROBIAL RISK ASSESSMENT IN CHEESE}

A microbial risk assessment is considered a scientific and methodical tool for preventing, regulating, and understanding the risk caused by hazardous microorganisms (EPA, 2012). The microbial risk assessment consists of four components: hazard identification, exposure assessment, hazard characterization, and risk characterization (Codex, 1999). This methodology has been used in many countries to prevent the occurrence of foodborne illnesses, to reduce the risk of foodborne illness outbreaks, and to establish microbial criteria. As discussed in previous sections, a number of cheese-related foodborne illness outbreaks have occurred. Additionally, cheese consumption has increased despite these foodborne illness outbreaks, which raised the necessity of microbial risk assessments on cheese (CDC, 2014d; USDA/ERS, 2014).

In New Zealand, the risk profiles prepared by Lake et al. (2005a,b) included elements of microbial risk assessment and the information related to risk management for $L$. monocytogenes in soft cheese and low moisture cheese. This work examined both risk assessment outcomes and action, in addition to providing a ranking of food safety issues. Lake et al. (2005a) suggested that additional risk management measures are unnecessary for low moisture cheeses $(<50 \%$ of moisture content) such as semi-soft cheese $(39 \%$ to $50 \%$ moisture; Stilton, Roquefort, Gorgonzola, Limburger, Gouda, Edam, etc.), hard cheese (less than 39\% moisture; Cheddar, Emmental, Gruyere, etc), and very hard cheese (less than $34 \%$ moisture content; Asiago old, Parmesan, Romano, Grana, etc) because of the low risks associated with $L$. monocytogenes exposure in the general population. A study by Lake et al. (2005b) presented that there is no evidence to link soft cheese consumption with cases of $L$. monocytogenes foodborne illness in New Zealand, and contamination rates of the pathogen were also very low in domestically produced soft cheese, but they suggested that the contamination with $L$. monocytogenes may occur in soft-ripened cheese after postharvest, especially during handling in ripening rooms, wrapping packing stage, and cutting stage. In addition, surface ripened cheese may be at risk because of increased $\mathrm{pH}$ during ripening. The FDA (2012a) completed a $L$. monocytogenes microbial risk assessment on soft-ripened cheese from pasteurized milk and raw milk in the USA and Canada. In this research report, quantitative models were used to predict the risk of L. monocytogenes in cheese, and to calculate the probability of invasive listeriosis per serving in soft-ripened cheese (Camembert-like cheese) that was produced using raw milk vs pasteurized milk. This report showed that the risk from raw milk cheese was higher than that of pasteurized milk cheese reflecting the higher contamination rate of raw milk. According to a report by CDC (2013c) soft cheese made with unpasteurized milk was estimated to be 50 to 160 times more likely to have L. monocytogenes infection than those made with pasteurized milk. However, only Camembertlike cheese was used for a quantitative risk assessment potentially limiting the scope of the model because other cheese may have different properties that affect $L$. monocytogenes growth. The risk of listeriosis from the cheese were $1.4 \times 10^{-10}, 7.2 \times 10^{-9}, 1.8 \times 10^{-8}$, and $6.1 \times 10^{-9}$ for non-susceptible individuals (general), the elderly, pregnant women, and immunocompromised patients in Canada, respectively, and $1.2 \times 10^{-10}, 7.3 \times 10^{-9}, 1.8 \times 10^{-8}$, and $5.2 \times 10^{-9}$ for identical groups in the USA, respectively. In addition, the risk of Camembert-like cheese made by raw milk was calculated for non-susceptible $\left(9.5 \times 10^{-9}\right.$ and $\left.1.8 \times 10^{-8}\right)$, elderly $\left(3.8 \times 10^{-7}\right.$ and $\left.8.2 \times 10^{-7}\right)$, pregnant women $\left(9.2 \times 10^{-7}\right.$ and $\left.1.8 \times 10^{-6}\right)$, and immunocompromised $\left(4.2 \times 10^{-7}\right.$ and $\left.8.1 \times 10^{-7}\right)$ individuals in the Canada and the USA, respectively. These results indicate that pregnant women, elderly individuals, and immunocompromised patients had a higher risk for listeriosis from Camembertlike cheese consumption (CDC, 2013a). In terms of relative risk, pregnant women are about 10 times more likely than the general population to get L. monocytogenes infection while the elderly ( 65 years and older) are about four times more likely than the general population to get $L$. monocytogenes infection (CDC, 2013b). Therefore, the CDC (2013c) categorized soft cheese made from raw milk such as Queso fresco, blue-veined, Feta, Brie, and Camembert cheeses into a higher risk group, but soft cheese made from pasteurized milk such as processed, cream and Mozzarella cheese, and hard cheese were categorized into the lower risk group. These microbial risk assessment studies indicate that raw milk soft cheese has higher risk than low moisture cheese for L. monocytogenes infection, especially for the elderly, pregnant women, and immunocompromised patients. Even though milk is pasteurized, soft cheese could be contaminated with $L$. monocytogenes due to postharvest contamination. In addition, the risk of selected hazards such as $C$. jejuni, $E$. coli, Salmonella spp., S. aureus, and L. monocytogenes of raw milk cheese was analyzed according to different types categorized into 'extra hard', 'Swiss', 'Cheddar', 'Blue', 'Feta', and 'Camembert'. Extra hard cheeses including Parmigiano Reggiano, Grana Padano, Sbrinz etc. have low moisture content $(<36 \%)$, and the risk represented a low to negligible. Swiss cheeses including Gruyere, Emmentaler, Appenzeller, Tilsiter, Tete de de Moine, and Vacherin 
Fribougeois had low to negligible risk but $L$. monocytogenes represented high risk to susceptible population. Cheddar cheese (moisture: $37 \%$ to $42 \%$ ) had high risk of $E$. coli to general and susceptible population because $E$. coli could survive during cheese making process and maturation, and other pathogens represented low to moderate in case of cheese made from sheep milk. Blue cheese ripened with mold had low risk of $L$. monocytogenes to general population and high risk to susceptible population because L. monocytogenes could increase in cheese making process. In cheese making process of Feta, $E$. coli might not decrease, which resulted in high risk of $E$. coli and also high risk of L. monocytogenes to susceptible population. Camembert (moisture: $>55 \%$ ) cheese showed high risk of $E$. coli to both general and susceptible population and the risks of $L$. monocytogenes were low to general and high to susceptible population, respectively, due to increasing bacterial counts in cheese making process and maturation (FSANZ, 2009).

Sanaa et al. (2004) conducted a quantitative risk assessment for L. monocytogenes based on data collected in 2000 to 2001 on Camembert and Brie cheeses (soft cheese) in France. For risk calculation, the behaviour of $L$. monocytogenes was predicted by mathematical and probabilistic models using a sequential scenario: cheese manufacturing, followed by distribution and storage. In addition, time series for temperature, consumption and dose-response were also used as part of the calculation. The growth of L. monocytogenes was calculated with a modified logistic model (Rosso, 1995). According to Monte Carlo simulations, $99 \%$ of iterations (total 10,000 iterations) resulted in less than 100 cells per serving $(3.7 \mathrm{~L}$. monocytogenes cells/g). Only $0.03 \%$ of Camembert and $0.22 \%$ of Brie cheeses had more than 100 L. monocytogenes cells $/ \mathrm{g}$, an acceptable level in several EU countries. Only $0.002 \%$ of Camembert and $0.05 \%$ of Brie cheese had more than $1,000 \mathrm{~L}$. monocytogenes cells/g. In addition, the calculated number of cases of severe listeriosis was $3.46 \times 10^{-3}$ and $5.11 \times 10^{-4}$ per 100 million servings of $27-\mathrm{g}$ Brie and Camembert cheese, respectively. This model thus estimated the number of severe listeriosis cases per year at $\leq 10^{-3}$ and $\leq 2.5 \times 10^{-3}$, given 17 million Brie and 480 million Camembert servings consumed per year. These results indicate that Brie cheese may have higher risk than that of Camembert cheese for $L$. monocytogenes infections. Although Brie and Camembert cheeses are almost identical for fermentation processing, the probability of severe listeriosis was higher in Brie cheese than in Camembert cheese. This may be caused by a higher prevalence of $L$. monocytogenes in Brie cheese than in Camembert cheese. Hence, it can be suggested that prevalence of foodborne pathogen in cheese significantly influence microbial risk.

STEC strains such as E. coli O157:H7, O26:H11,
O111:H8, and O145:H28 are able to survive and grow during cheese processing, especially in soft cheese. Perrin et al. (2015) developed a quantitative risk assessment for STEC strains that cause haemolytic uremic syndrome. This research utilized a stochastic model to determine the effect of preharvest and postharvest interventions on the risk of raw milk soft cheese consumption in France. Predicted average percentages of contaminated cheese at baseline were $16.31 \%$ and $1.75 \%$ for total STEC and five main pathogenic serotypes of STEC (MPS-STEC; O157:H7, O26:H11, O103:H2, O111:H8, and O145:H28), respectively. The levels of contamination of servings were $0.12 \mathrm{CFU} / \mathrm{g}$ for STEC and $0.21 \mathrm{CFU} / \mathrm{g}$ for MPS-STEC. In addition to this baseline simulation, Perrin et al. (2015) simulated preharvest prevention and postharvest prevention, and the risk reduction varied from $1 \%$ to $96 \%$ with the combination of preventions. Thus, preharvest and postharvest treatments need to be applied to reduce the microbial risk.

Lindqvist et al. (2002) carried out quantitative microbial risk assessment for unripened cheese from raw milk to estimate the risk of $S$. aureus outbreaks at this time of consumption. This research showed that based on the mean or median value of parameters, the estimated levels of $S$. aureus were under the threshold in unripened cheese, whereas they were above the threshold in the worst-case scenario simulation. For risk characterization, a doseresponse model for $S$. aureus enterotoxin was not considered in this study because the dose-response model does not exist. Hence, the threshold (6 Log CFU/g) for staphylococcal enterotoxin production was used instead of using a dose-response model for enterotoxin. This method could be considered an appropriate alternative for $S$. aureus risk assessment (FDA, 2012b). In addition, this risk assessment suggested that starter cultures in the cheese making process possibly affect the microbial risk.

In conclusion, although cheese is considered microbiologically safe, cheese-borne outbreaks have still occurred, especially in soft cheese. Predictive models have been used to determine the factors related to bacterial growth such as $\mathrm{pH}$ and $\mathrm{Aw}$, and the results from predictive models are used in microbial risk assessment in many countries to uncover cheese that might pose risks to consumers. The microbial risk assessment then showed that microbial risk increased in cheese with high moisture content, especially for raw milk cheese. However, applications of preharvest and postharvest preventions can reduce the microbial risk. Even though microbial risk assessments were conducted for cheese, in some studies limited data were used for predictive models, temperature profile for distribution and consumption patterns as well as dose-response model, especially for susceptible group such as elderly, pregnant women, and immunocompromised individuals. Therefore, more predictive models in cheese- 
related conditions, dose-response models need to be developed in conjunction with greater collection of consumption data to improve the performance of cheese microbial risk assessment. In addition, the results from microbial risk assessment should be further used for appropriate level of protection and food safety objective, which are for applications on microbial criteria.

\section{CONFLICT OF INTEREST}

We certify that there is no conflict of interest with any financial organization regarding the material discussed in the manuscript.

\section{REFERENCES}

Altekruse, S. F., B. B. Timbo, J. C. Mowbray, N. H. Bean, and M. E. Potter. 1998. Cheese-associated outbreaks of human illness in the United States, 1973 to 1992: Sanitary manufacturing practices protect consumers. J. Food Prot. 61:1405-1407.

Bille, J., D. S. Blanc, H. Schmid, K. Boubaker, A. Baumgartner, H. H. Siegrist, M. L. Tritten, R. Lienhard, D. Berner, R. Anderau, M. Treboux, J. M. Ducommun, R. Malinverni, D. Genné, P. H. Erard, and U. Waespi. 2006. Outbreak of human listeriosis associated with tomme cheese in northwest Switzerland, 2005. Euro Surveill. 11:91-93.

Bozkurt, H. and O. Erkmen. 2001. Predictive modeling of Yersinia enterocolitica inactivation in Turkish Feta cheese during storage. J. Food Eng. 47:81-87.

CDC (Centers for Disease Control and Prevention). 2001. Outbreak of listeriosis associated with homemade Mexicanstyle cheese-North Carolina, October 2000-January 2001. MMWR Morb. Mortal. Wkly. Rep. 50:560-562.

CDC (Centers for Disease Control and Prevention). 2008. Outbreak of multidrug-resistant Salmonella enterica serotype Newport infections associated with consumption of unpasteurized Mexican-style aged cheese-Illinois, March 2006-April 2007. MMWR Morb. Mortal. Wkly. Rep. 57:432435.

CDC (Centers for Disease Control and Prevention). 2010a. Staphylococcal food poisoning. http://www.cdc.gov/nczved/ divisions/dfbmd/diseases/staphylococcal/ Accessed January 6, 2015.

CDC (Centers for Disease Control and Prevention). 2010b. Investigation update: Multistate outbreak of E. coli O157:H7 infections associated with cheese. http://www.cdc.gov/ecoli/ 2010/cheese0157/archive/111210.html Accessed January 8, 2015.

CDC (Centers for Disease Control and Prevention). 2013a. Listeria (Listeriosis). http://www.cdc.gov/listeria/risk.html Accessed January 12, 2015.

CDC (Centers for Disease Control and Prevention). 2013b. Vital signs: Listeria illnesses, deaths, and outbreaks - United States, 2009-2011. MMWR Morb. Mortal. Wkly. Rep. 62:448-452.

CDC (Centers for Disease Control and Prevention) 2013c Listeria and food. http://www.cdc.gov/foodsafety/specificfoods/listeria-and-food.html Accessed January 21, 2015.
CDC (Centers for Disease Control and Prevention). 2014a. Foodborne outbreak online database. http://wwwn.cdc.gov/ foodborneoutbreaks/Default.aspx\# Accessed January 6, 2015.

CDC (Centers for Disease Control and Prevention). 2014b. Multistate outbreak of listeriosis linked to Roos Foods dairy products (final update). http://www.cdc.gov/listeria/outbreaks/ cheese-02-14/ Accessed January 9, 2015.

CDC (Centers for Disease Control and Prevention). 2014c. Multistate outbreak of Salmonella Stanley Infections linked to raw Cashew cheese (final update). http://www.cdc.gov/ salmonella/stanley-01-14/ Accessed January 8, 2015.

CDC (Centers for Disease Control and Prevention). 2014d. List of Selected Multistate Foodborne Outbreak Investigations. http://www.cdc.gov/foodsafety/outbreaks/multistate-outbreaks/ outbreaks-list.html Accessed January 4, 2014.

CDIC (Canadian Dairy Information Centre). 2014. Global consumption per capita of dairy products: Total cheese consumption. http://www.dairyinfo.gc.ca/index_e.php?s1=dfffcil\&s2=cons\&s3=consglo\&s4=tc-ft Accessed January 5, 2015.

CCE (Clemson Cooperative Extension). 2008. Handling of cheese for safety \& quality. http://www.clemson.edu/extension/hgic/ food/pdf/hgic3506.pdf Accessed July 29, 2015.

Codex. 1999. Principles and guidelines for the conduct of microbiological risk assessment. CAC/GL-30. http://www.fao.org/docs/eims/upload/215254/CAC_GL30.pdf Accessed December 28, 2014.

Codex. 2000. Codex general standard for cheese (Codex Standard 283-1978). http://www.ianunwin.demon.co.uk/eurocode/ foodinfo/codex/cdx-cheesetype.htm Accessed January 15, 2015.

Delbes, C., J. Alomar, N. Chougui, J. F. Martin, and M. C. Montel. 2006. Staphylococcus aureus growth and enterotoxin production during the manufacture of uncooked, semihard cheese from cows' raw milk. J. Food Prot. 69:2161-2167.

European Commission. 2007. Commission regulation EC No 1441/2007 of 5 December 2007. OJEU. 322:12-29.

EFSA/ECDC (European Food Safety Authority/European Centre for Disease Prevention and Control). 2011. The European Union summary report on trends and sources of zoonosis, zoonotic agents and food-borne outbreaks in 2009. EFSA J. 9:2090

FDA (Food and Drug Administration). 2003. Quantitative assessment of relative risk to public health from foodborne Listeria monocytogenes among selected categories of ready-toeat foods. http://www.fda.gov/downloads/Food/ FoodScienceResearch/UCM197330.pdf Accessed January 5, 2014.

FDA (Food and Drug Administration). 2012a. Joint FDA/Health Canada quantitative assessment of the risk of listeriosis from soft-ripened cheese consumption in the United States and Canada: draft interpretative summary. http://www.fda.gov/ downloads/Food/FoodScienceResearch/UCM338618.pdf. Accessed January 5, 2015.

FDA (Food and Drug Administration). 2012b. Bad Bug Book: Handbook of foodborne pathogenic microorganisms and natural toxins. http://www.fda.gov/downloads/Food/ FoodborneIllnessContaminants/UCM297627.pdf Accessed January 12, 2015.

FDA/USDA (Food and Drug Administration/U.S. Department of 
Agriculture). 2003. Quantitative assessment of the relative risk to public health from foodborne Listeria monocytogenes among selected categories of ready-to-eat foods. http://www.fda.gov/downloads/Food/FoodScienceResearch/U CM197329 pdf Accessed January 5, 2015.

Food Standards. 2009. Microbiological risk assessment of raw milk cheese. http://www.foodstandards.gov.au/code/proposals/ documents/P1007\%20PPPS\%20for\%20raw\%20milk\%201AR \%20SD3\%20Cheese\%20Risk\%20Assessment.pdf Accessed January 5, 2015.

Fratamico, P. M. and D. O. Bayles. 2005. Molecular approaches for detection, identification, and anlysis of foodborne pathogens. In: Foodborne pathogens: Microbiology and molecular biology (Eds. P. M. Fratamico, A. K. Bhunia, and J. L. Smith). Caister Academic Press, Norfolk, UK. pp. 1-14.

Fretz, R., U. Sagel, W. Ruppitsch, A. T. Pietzka, A. Stöger, S. Huhulescu, S. Heuberger, J. Pichler, P. Much, G. Pfaff, K. Stark, R. Prager, A. Flieger, O. Feenstra, and F. Allerberger. 2010. Listeriosis outbreak caused by acid curd cheese 'Quargel', Austria and Germany 2009. Euro Surveill. 15:pii $=19477$.

Genigeorgis, C., M. Carniciu, D. Dutulescu, and T. B. Farver. 1991. Growth and survival of Listeria monocytogenes in market cheeses stored at 4 to $30^{\circ} \mathrm{C}$. J. Food Prot. 54:662-668.

Goldin, B. R. and S. L. Gorbach. 1992. Probiotics for humans. In. Probiotics. The scientific basis (Ed. R. Fuller) Chapman \& Hall, London, UK. pp. 355-376. http://dx.doi.org/10.1007/97894-011-2364-8 13

Gould, L. H., E. Mungai, and C. B. Behravesh. 2014. Outbreaks attributed to cheese: Differences between outbreaks caused by unpasteurized and pasteurized dairy products, United States, 1998-2011. Foodborne Pathog. Dis. 11:545-551.

Gyles, C. L. 2007. Shiga toxin-producing Escherichia coli: An overview. J. Anim. Sci. 85(13 Suppl):E45-E62.

Honish, L., G. Predy, N. Hislop, L. Chui, K. KowalewskaGrochowska, L. Trottier, C. Kreplin, and I. Zazulak. 2005. An outbreak of E. coli O157:H7 hemorrhagic colitis associated with unpasteurized Gouda cheese. Can. J. Public Health. 96:182-184.

Institute of Medicine (US) Committee to Review Dietary Reference Intakes for Vitamin D and Calcium; A. C. Ross, C. L. Taylor, A. L. Yaktine, and H. B. Del Valle. 2011. Dietary reference intakes for calcium and vitamin D. National Academies Press, Washington, DC, USA.

Jackson, K. A., M. Biggerstaff, M. Tobin-D'Angelo, D. Sweat, R. Klos, J. Nosari, O. Garrison, E. Boothe, L. Saathoff-Huber, L. Hainstock, and R. P. Fagan. 2011. Multistate outbreak of Listeria monocytogenes associated with Mexican-style cheese made from pasteurized milk among pregnant, Hispanic women. J. Food Prot. 74:949-953.

Janštovă, B., L. Necidová, A. Skočková, and B. Janštová. 2014. Staphylococcal enterotoxin production in model samples of milk and fresh cheese. J. Food Nutr. Res. 53:389-392.

Johnson, M. E. 2001. Cheese products. In: Applied dairy microbiology, 2nd ed. (Eds. E. H. Marth and J. L. Steele). Marcel Dekker, Inc., New York, NY, USA. pp. 345-384.

Kathariou, S. 2002. Listeria monocytogenes virulence and pathogenicity, a food safety perspective. J. Food Prot. 65:18111829.
Kosikowski, F. and V. V. Mistry. 1997. Cheese and fermented milk foods. 3rd edn. F. V. Kosikowski, Westport, CT, USA.

Kousta, M., M. Mataragas, P. Skandamis, and E. H. Drosinos. 2010. Prevalence and sources of cheese contamination with pathogens at farm and processing levels. Food Control 21:805815.

Kowalik, J. and A. Lobacz. 2015. Development of predictive model describing the growth of Yersinia enterocolitica in Camembert-type chees. Int. J. Food Sci. Technol. 50:811-818.

Lake, R., A. Hudson, P. Cressey, and S. Gilbert. 2005a. Risk profile: Listeria monocytogenes in low moisture cheeses. Client report FW0440 of New Zealand Food Safety Authority. http://www.foodsafety.govt.nz/elibrary/industry/Risk_Profile Listeria_Monocytogenes-Science_Research.pdf Accessed January 5, 2015.

Lake, R., A. Hudson, P. Cressey, and S. Gilbert. 2005b. Risk profile: Listeria monocytogenes in soft cheeses. Client report FW0382 of New Zealand Food Safety Authority. http://www.foodsafety.govt.nz/elibrary/industry/Risk_Profile Listeria_Monocytogenes_Soft-Science_Research.pdf Accessed January 5, 2015.

Le Loir, Y., F. Baron, and M. Gautier. 2003. Staphylococcus aureus and food poisoning. Genet. Mol. Res. 2:63-67.

Lee, H., K. Kim, S. Lee, M. Han, and Y. Yoon. 2014. Growth kinetics of Staphylococcus aureus on Brie and Camembert cheeses. J. Dairy Res. 81:252-256.

Lindqvist, R., S. Sylven, and I. Vagsholm. 2002. Quantitative microbial risk assessment exemplified by Staphylococcus aureus in unripened cheese made from raw milk. Int. J. Food Microbiol. 78:155-170.

Maguire, H. C., M. Boyle, M. J. Lewis, J. Pankhurst, A. A. Wieneke, M. Jacob, J. Bruce, and M. O'Mahony. 1991. A large outbreak of food poisoning of unknown aetiology associated with Stilton cheese. Epidemiol. Infect. 106:497-505.

Makino, S. I., K. Kawamoto, K. Takeshi, Y. Okada, M. Yamasaki, S. Yamamoto, and S. Igimi. 2005. An outbreak of food-borne listeriosis due to cheese in Japan, during 2001. Int. J. Food Microbiol. 104:189-196.

MDA (Missouri Department of Agriculture). 2010. Missouri agriculture, health officials investigate reports of bacteria found in Missouri cheese sold in California. http://agriculture.mo.gov/news/2010/Missouri_Agriculture_He alth_Officials_Investigate_Reports_of_Bacteria_Found_in_Mi ssouri_Cheese_Sold_in_California Accessed January 4, 2015.

Moreno-Enriquez, R. I., A. Garcia-Galaz, E. Acedo-Felix, I. H. Gonzalez-Rios, J. E. Call, J. B. Luchansky, and M. E. DiazCinco. 2007. Prevalence, types, and geographical distribution of Listeria monocytogenes from a survey of retail Queso Fresco and associated cheese processing plants and dairy farms in Sonora, Mexico. J. Food Prot. 70:2596-2601.

Moustafa, M. K. 1990. Isolation of Yersinia enterocolitica from raw milk and soft cheese in Assiut city. Assiut Vet. Med. J. 23:106-109.

Mozaffarian, D., H. Cao, I. B. King, R. N. Lemaitre, X. Song, D. S. Siscovick, and G. S. Hotamisligil. 2010. Trans-palmitoleic acid, metabolic risk factors, and new-onset diabetes in U.S. adults: A cohort study. Ann. Intern. Med. 153:790-799.

Normanno, G., G. La Salandra, A. Dambrosio, N. C. Quaglia, M. Corrente, A. Parisi, G. Santagada, A. Firinu, E. Crisetti, and G. 
V. Celano. 2007. Occurrence, characterization and antimicrobial resistance of enterotoxigenic Staphylococcus aureus isolated from meat and dairy products. Int. J. Food Microbiol. 115:290-296.

Northolt, M. D. 1984. Growth and inactivation of pathogenic microorganisms during manufacture and storage of fermented dairy products: A review. Neth. Milk Dairy J. 38:135-150.

Ostyn, A., M. L. De Buyser, F. Guillier, J. Groult, B. Félix, S. Salah, G. Delmas, and J. A. Hennekinne. 2010. First evidence of a food poisoning outbreak due to staphylococcal enterotoxin type E, France, 2009. Euro Surveill. 15:pii=19528.

Pelisser, M. R., C. S. Klein, K. R. Ascoli, T. R. Zotti, and A. C. Arisi. 2009. Ocurrence of Staphylococcus aureus and multiplex PCR detection of classic enterotoxin genes in cheese and meat products. Braz. J. Microbiol. 40:145-148.

Perrin, F., F. Tenenhaus-Aziza, V. Michel, S. Miszczycha, N. Bel, and M. Sanaa. 2015. Quantitative risk assessment of haemolytic and uremic syndrome linked to O157:H7 and nonO157:H7 shiga-toxin producing Escherichia coli strains in raw milk soft cheeses. Risk Anal. 35:109-128.

Rabello, R. F., B. M. Moreira, R. M. Lopes, L. M. Teixeira, L. W. Riley, and A. C. Castro. 2007. Multilocus sequence typing of Staphylococcus aureus isolates recovered from cows with mastitis in Brazilian dairy herds. J. Med. Microbiol. 56(Pt 11):1505-1511.

Reiter, B., B. G. Fewins, T. F. Fryer, and M. E. Sharpe. 1964. Factors affecting the multiplication and survival of coagulase positive Staphylococci in Cheddar cheese. J. Dairy Res. 31:261-272.

Rosshaug, P. S., A. Detmer, H. Ingmer, and M. H. Larsen. 2012. Modeling the growth of Listeria monocytogenes in soft bluewhite cheese. Appl. Environ. Microbiol. 78:8505-8514.

Rosso, L. 1995. Modeling and Predictive Microbiology: Development of a New Tool for the Food Industry. Ph.D. Thesis, University Claude Bernard, Lyon, France.

Ryser, E. T. 2001. Public Health Concerns. In: Applied dairy microbiology, 2nd ed. (Eds. E. H. Marth and J. L. Steele). Marcel Dekker, Inc., New York, NY, USA. pp. 397-546.

Ryser, E. T. and E. H. Marth. 1987a. Behavior of Listeria monocytogenes during the manufacture and ripening of cheddar cheese. J. Food Prot. 50:7-13.

Ryser, E. T. and E. H. Marth. 1987b. Fate of Listeria monocytogenes during the manufacture and ripening of Camembert cheese. J. Food Prot. 50:372-378.

Sanaa, M., L. Coroller, and O. Cerf. 2004. Risk assessment of listeriosis linked to the consumption of two soft cheeses made from raw milk: Camembert of Normandy and Brie of Meaux. Risk Anal. 24:389-399.
Schvartzman, M. S., U. Gonzalez-Barron, F. Butler, and K. Jordan. 2014. Modeling the growth of Listeria monocytogenes on the surface of smear-or mold-ripened cheese. Front. Cell Infect. Microbiol. 4:90.

Simeão do Carmoa, L., R. Souza Dias, V. R. Linardi, M. José de Sena, D. Aparecida dos Santos, M. Eduardo de Faria, E. Castro Pena, M. Jett, and L. Guilherme Heneine. 2002. Food poisoning due to enterotoxigenic strains of Staphylococcus present in Minas cheese and raw milk in Brazil. Food Microbiol. 19:9-14.

USDA/ARS (U.S. Department of Agriculture/Agricultural Research Service). 2011. National nutrient database for standard reference release 27. http://ndb.nal.usda.gov/ndb/ Accessed January 5, 2015.

USDA/ERS (U.S. Department of Agriculture/Economic Research Service). 2014. Dairy products: Per capita consumption, United State (Annual). http://www.ers.usda.gov/dataproducts/dairy-data.aspx Accessed January 15, 2015.

EPA (U.S. Environmental Protection Agency). 2012. Microbial risk assessment guideline: pathogenic microorganisms with focus on food and water. http://nepis.epa.gov/Exe/ZyNET.exe/P100EQP4.TXT?ZyActio $\mathrm{nD}=\mathrm{ZyD}$ Document $\&$ Client $=$ EPA $\&$ Index $=2011+\mathrm{Thru}+2015 \&$ Do $\mathrm{cs}=\&$ Query $=\&$ Time $=\&$ EndTime $=\&$ SearchMethod $=1 \&$ TocRes trict $=$ n $\&$ Toc $=\&$ TocEntry $=\& Q$ Field $=\& Q$ FieldYear $=\& Q$ FieldM onth $=\& Q$ FieldDay $=\&$ IntQFieldOp $=0 \&$ ExtQFieldOp $=0 \& X m 1$ Query $=\&$ File $=D \% 3 \mathrm{~A} \% 5$ Czyfiles $\% 5$ CIndex $\% 20$ Data $\% 5 \mathrm{C} 11$ th ru15\%5CTxt\%5C00000005\%5CP100EQP4.txt\&User=ANON YMOUS\&Password=anonymous \&SortMethod $=\mathrm{h} \% 7 \mathrm{C}-$ $\&$ MaximumDocuments $=1 \&$ FuzzyDegree $=0 \&$ ImageQuality $=\mathrm{r}$ 75g8/r75g8/x150y150g16/i425\&Display=p\%7Cf\&DefSeekPa $\mathrm{ge}=\mathrm{x} \&$ SearchBack $=$ ZyActionL\&Back=ZyActionS\&BackDesc $=$ Results\%20page \&MaximumPages $=1 \& Z y$ Entry $=1 \&$ SeekPag $\mathrm{e}=\mathrm{x} \& Z y$ PURL Accessed January 4, 2015.

van Cauteren, D., N. Jourdan-da Silva, F. X. Weill, L. King, A. Brisabois, G. Delmas, V. Vaillant, and H. de Valk. 2009. Outbreak of Salmonella Enterica serotype Muenster infections associated with goat's cheese, France March 2008. Euro Surveill. 14:pii=19290.

Wing, E. J. and S. H. Gregory. 2002. Listeria monocytogenes: Clinical and experimental update. J. Infect. Dis. 185(Suppl 1):S18-S24.

Yousef, A. E. and E. H. Marth. 1988. Behavior of Listeria monocytogenes during the manufacture and storage of Colby cheese. J. Food Prot. 51:12-15. 